\title{
Hypofractionation and prostate cancer: A good option for Africa?
}

\begin{tabular}{|c|c|}
\hline $\begin{array}{l}\text { Authors: } \\
\text { Luca Incrocci }{ }^{1} \\
\text { Ben Heijmen } \\
\text { Patrick Kupeli } \\
\text { Hannah M. Sir }\end{array}$ & $\begin{array}{l}\text { (1) } \\
\text { (1) } \\
n^{2} \text { (1) } \\
\text { nonds }\end{array}$ \\
\hline $\begin{array}{l}\text { Affiliations: } \\
{ }^{1} \text { Department } \\
\text { Oncology, Era } \\
\text { Cancer Institu } \\
\text { Netherlands }\end{array}$ & $\begin{array}{l}\text { ff Radiation } \\
\text { mus MC } \\
\text { te, the }\end{array}$ \\
\hline $\begin{array}{l}{ }^{2} \text { Department } \\
\text { Oncology, Dav } \\
\text { School of Mec } \\
\text { University of } \\
\text { Angeles, Unit }\end{array}$ & $\begin{array}{l}\text { ff Radiation } \\
\text { id Geffen } \\
\text { licine, } \\
\text { alifornia, Los } \\
\text { d States }\end{array}$ \\
\hline $\begin{array}{l}{ }^{3} \text { Division of Ra } \\
\text { Oncology, Ste } \\
\text { University, Tyg } \\
\text { Hospital, Sout }\end{array}$ & $\begin{array}{l}\text { diation } \\
\text { lenbosch } \\
\text { erberg } \\
\text { h Africa }\end{array}$ \\
\hline $\begin{array}{l}\text { Correspondin } \\
\text { Luca Incrocci, } \\
\text { l.incrocci@era }\end{array}$ & $\begin{array}{l}\text { g author: } \\
\text { smusmc.nl }\end{array}$ \\
\hline $\begin{array}{l}\text { Dates: } \\
\text { Received: } 17 \text { J } \\
\text { Accepted: } 03 \\
\text { Published: } 29\end{array}$ & $\begin{array}{l}\text { uly } 2017 \\
\text { Aug. } 2017 \\
\text { Aug. } 2017\end{array}$ \\
\hline $\begin{array}{l}\text { How to cite th } \\
\text { Incrocci L, Heij } \\
\text { Kupelian P, Sin } \\
\text { Hypofractiona } \\
\text { prostate cance } \\
\text { option for Afri } \\
\text { oncol. 2017;1( } \\
\text { doi.org/10.41C }\end{array}$ & $\begin{array}{l}\text { is article: } \\
\text { men B, } \\
\text { londs HM. } \\
\text { tion and } \\
\text { r: A good } \\
\text { ca? S. Afr. j. } \\
\text { 0), a28. https:// } \\
\text { 2/sajo.v1i0.28 }\end{array}$ \\
\hline $\begin{array}{l}\text { Copyright: } \\
\text { @ 2017. The } A \\
\text { Licensee: AOS } \\
\text { is licensed unc } \\
\text { Creative Comr } \\
\text { Attribution Lic }\end{array}$ & $\begin{array}{l}\text { uthors. } \\
\text { S. This work } \\
\text { ler the } \\
\text { nons } \\
\text { ense. }\end{array}$ \\
\hline Read online: & \\
\hline 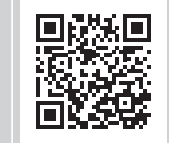 & $\begin{array}{l}\text { Scan this QR } \\
\text { code with your } \\
\text { smart phone or } \\
\text { mobile device } \\
\text { to read online. }\end{array}$ \\
\hline
\end{tabular}

\section{Authors:}

Patrick Kupelian ${ }^{2}$

Hannah M. Simonds

Affiliations:

Oncology, Erasmus

Cancer Institute, the

${ }^{2}$ Department of Radiation

Oncology, David Geffe

School of Medicine,

University of California, Los

${ }^{3}$ Division of Radiation

Oncology, Stellenbosch

University, Tygerberg

Corresponding author:

Luca Incrocci,

Dates:

Accepted: 03 Aug. 2017

How to cite this article: Incrocci L, Heijmen B,

Kupelian P, Simonds HM.

Hypofractionation and

option for Africa? S. Afr.

oncol. 2017;1(0), a28. https://

Copyright:

(c) 2017. The Authors.

is licensed under the

Creative Commons

Attribution License.

mobile device
to read online.

\begin{abstract}
Cancer is an emerging public health problem in Africa. According to the World Health Organization, the numbers will be doubled by 2030 because of the ageing and the growth of the population. Prostate cancer is the most common cancer among men in most African countries. Radiotherapy machines are extremely limited in Africa and therefore prostate cancer in Africa is mostly managed by urologists. However, for a large proportion of prostate cancer patients, external-beam radiotherapy (EBRT) will be the treatment of choice in Africa because of limitations of surgical expertise in many countries. The disparity between the $\alpha / \beta$ ratio for late complications and the low $\alpha / \beta$ ratio for prostate cancer widens the therapeutic window when treating prostate cancer with hypofractionation. Because of the reduced number of treatment days, hypofractionation offers economic and logistic advantages, reducing the burden of the very limited radiotherapy resources in most African countries. It also increases patient convenience. A misleading assumption is that high-level radiotherapy is not feasible in low-income countries. The gold standard option for hypofractionation includes daily imageguided radiotherapy with 3-4 implanted gold fiducials. Acceptable methods for image guidance include ultrasound and cone-beam computed tomography (CT). CT-based treatment planning with magnetic resonance imaging fusion allows for accurate volume delineation. Volumetric modulated arc therapy or inversely planned intensity modulated radiotherapy is the ideal for treatment delivery. The most vital component is safe delivery, which necessitates accurate quality assurance measures and on-board imaging. We will review the evidence and potential utilisation of hypofractionated EBRT in Africa.
\end{abstract}

\section{Introduction}

Cancer is an emerging public health problem in Africa. According to the World Health Organization (WHO), the numbers will be doubled by 2030 because of the ageing and the growth of the population. Cancer prevention strategies are limited in Africa; therefore, most cancers are diagnosed at an advanced stage. ${ }^{1}$ A shortage of medical specialists, nurses and pathology workers contributes to a late presentation and low attendance in hospitals. Several new cancer registries have been established in Africa in the past 10 years. Prostate cancer is the most common cancer among men in most African countries. $^{2}$ Data from Zimbabwe demonstrate the increasing trend in prostate cancer incidence throughout Africa. ${ }^{2,3}$ All these countries share a common 'Westernisation' of lifestyles among their urban populations, suggesting the role of environmental factors such as diet (high fish content and low animal fat replaced by Western diet containing high animal fat). ${ }^{4}$ Radiotherapy machines are extremely limited in Africa and therefore prostate cancer in Africa is mostly managed by urologists. However, for a large proportion of prostate cancer patients, external-beam radiotherapy (EBRT) will be the treatment of choice in Africa because of limitations of surgical expertise in many countries.

An important biological parameter describing the response of tissues to fractionation is the repair capacity $(\alpha / \beta$ ratio). Late responding tissues are characterised by a relatively low $\alpha / \beta$ ratio (3-4 Gy), resulting in an enhanced sensitivity for large fraction doses. Acute responding healthy tissues and most tumours are characterised by a high $\alpha / \beta$ ratio (10 Gy) and therefore are relatively insensitive to large fraction doses, compared to tissues with low $\alpha / \beta$ ratio. Prostate cancer has a highly atypical growth pattern in comparison with other malignancies and has a low $\alpha / \beta$ ratio, probably even lower than late responding healthy tissues. ${ }^{5}$ The disparity between the $\alpha / \beta$ ratio for late complications and the low $\alpha / \beta$ ratio for prostate cancer widens the therapeutic window by treating prostate cancer with hypofractionation. Hypofractionated schedules for prostate cancer have been used for many years, but only recently several randomised clinical trials have been published to study the possibility of a high therapeutic gain delivering a higher biological dose to the prostate without increasing toxicity. The question raised here is: could this shortened schedule find a place in radiation delivery in resource-constrained settings? This perspective will review the evidence and potential utilisation of hypofractionated EBRT in Africa. 


\section{Hypofractionation trials}

A variety of schedules have been tested in clinical trials (see Table 1). The Dutch HYPRO trial randomised 820 intermediate- to high-risk patients to 39 fractions of 2 Gy (5 fractions/week) or 19 fractions of 3.4 Gy (3 fractions/ week). ${ }^{6}$ This study was designed to test whether an equivalent increased dose of 12.4 Gy in 2-Gy fractions using hypofractionated EBRT would achieve a significant increase in relapse-free survival (RFS) of $10 \%$ as compared to conventional treatment. ${ }^{6}$ At a median follow-up of 60 months, no significant differences in RFS were achieved with rates of $80 \%$ and $77 \%$ after hypofractionation and conventional fractionation, respectively.

The CHHiP trial randomised 3216 patients with intermediateor high-risk prostate cancer to conventional fractionation of 74 Gy in 37 fractions or two hypofractionation schedules: 57 Gy in 19 fractions or 60 Gy in 20 fractions. ${ }^{7}$ Hypofractionated treatment using $60 \mathrm{~Gy}$ in 20 fractions was found non-inferior to conventional treatment with 5-year RFS rates of $88 \%$ and 91\% after conventional and hypofractionated treatment, respectively. The $57 \mathrm{~Gy}$ schedule was found to be inferior. The RTOG 0415 trial also demonstrated non-inferiority of hypofractionated EBRT of $70 \mathrm{~Gy}$ in 28 fractions versus $73.8 \mathrm{~Gy}$ in 41 fractions in 1115 patients with low-risk prostate cancer. ${ }^{8}$

There was significantly more acute grade $\geq 2$ bowel toxicity during treatment in the CHHiP and the HYPRO trials; however, the observed differences between arms had dissipated after completion of treatment. ${ }^{6,7}$ In contrast to bowel toxicity, all trials reported comparable acute bladder toxicities between treatment schemes. In terms of late toxicity, both the RTOG 0415 and the HYPRO trials demonstrated increased grade $\geq 2$ bowel and bladder toxicity with hypofractionated EBRT as compared to conventional treatment. ${ }^{6,8}$ In contrast, the $\mathrm{CHHiP}$ trial did not find any difference in late toxicity between the arms and the authors concluded that their hypofractionated regimen of 60 Gy in 3-Gy fractions should be considered as new standard of care for EBRT of localised prostate cancer. ${ }^{7}$ The increase in late toxicity in the HYPRO trial was limited; for example, grade 3 nocturia ( $\geq 6$ times/night) was reported in $19 \%$ after hypofractionation versus $13 \%$ in the conventional arm. ${ }^{6}$ It is questionable whether these differences are clinically relevant. Patients might prefer a slightly increased toxicity risk if the number of hospital visits can be reduced. Very recently, Catton et al. reported on 1206 patients with intermediate-risk prostate cancer and without anti-androgen therapy (ADT), randomised to $39 \times 2 \mathrm{~Gy}$ and $20 \times 3 \mathrm{~Gy} .{ }^{9}$ The hypofractionated

TABLE 1: Hypofractionated protocols.

\begin{tabular}{llcc}
\hline Risk group & Stage & Schedule & Reference \\
\hline Intermediate-high risk & CT1b-T4, any Gleason sum, & $\begin{array}{c}19 \times 3.4 \mathrm{~Gy} \\
3 \text { weekly }\end{array}$ & 6 \\
& PSA $\leq 60 \mu \mathrm{g} / \mathrm{L}$ & \\
Intermediate-high risk & CT1b-T3a, any Gleason sum, & $\begin{array}{c}20 \times 3 \mathrm{~Gy} \\
5 \text { weekly }\end{array}$ & 7 \\
& PSA $\leq 30 \mu \mathrm{g} / \mathrm{L}$ & \multirow{2}{*}{$\begin{array}{c}5 \times 7 \mathrm{~Gy} \\
\text { Low risk }\end{array}$} & 10 \\
& CT1-2b, Gleason sum $\leq 6$, & weekly & \\
\hline
\end{tabular}

Source: Authors' own work regimen was not inferior to conventional radiotherapy and was not associated with increased late toxicity. The authors concluded that the hypofractionated schedule is more convenient for patients and therefore should be considered for intermediate-risk prostate cancer. ${ }^{9}$ Patient selection is paramount when considering hypofractionation. Those men with compromised urinary function at baseline were at risk of late bladder toxicity, ${ }^{6}$ and therefore they might not be the right patients to prescribe hypofractionation.

Regarding erectile functioning, the HYPRO trial showed no significant differences between treatment arms in patients who received no or short-term ADT.

Stereotactic body radiotherapy (SBRT) delivered using gantry-based Linacs is an example of profound hypofractionation, using dose fractions of 5-10 Gy. Several small studies, mainly phase II non-randomised studies, including only low-stage prostate cancer, have been recently published. ${ }^{10,11,12,13}$ Current clinical data provide excellent short-term control rates for SBRT; toxicity induced by SBRT at the more established fraction dose of 5-8 Gy $y^{10,12,13}$ does not appear to be substantially higher as compared to conventional treatments. Future randomised trials will help determine the efficacy and safety of SBRT.

\section{Why consider hypofractionation in Africa?}

Hypofractionation offers economic and logistic advantages, reducing the burden of the very limited radiotherapy resources in most African countries. It also increases patient convenience. A misleading assumption is that the required high-level radiotherapy is not feasible in low-income countries because of costs, lack of electricity, poor transport, geopolitical instability, lack of specialised staff, and education and training activities; however, this does not hold true in all countries. ${ }^{14}$ Education of technical personnel and staff is feasible. Ongoing quality assurance can be supported through web-based systems, with teleconferencing in a sister institution either in Europe or in the USA. Several studies have been performed on automated treatment plan generation for prostate cancer. ${ }^{15,16}$ Generally, the automatically generated plans are considered similar or of higher quality compared to plans generated with conventional trial-anderror planning. Automated treatment planning, performed in collaboration with a partner institute to guarantee high plan quality, might be investigated. The most vital component is safe delivery which necessitates accurate quality assurance measures and on-board imaging. ${ }^{17}$

\section{Technical requirements for hypofractionation}

The gold standard option includes image-guided radiotherapy with 3-4 implanted gold fiducials. Acceptable methods for image guidance include ultrasound and cone-beam computed tomography (CT). CT-based treatment planning with magnetic resonance imaging fusion allows for accurate 
volume delineation. Volumetric modulated arc therapy (VMAT) or inversely planned intensity modulated radiotherapy (IMRT) is the ideal for treatment delivery. Position verification prior to every fraction with electronic kilovoltage or megavoltage portal imaging or X-ray volumetric imaging ensures accurate delivery.

A reasonable option whether or not VMAT or IMRT techniques are available is modified forward planning with the field-infield technique, or three-dimensional conformal therapy with higher energies.

In resource-constrained settings, setup verification with daily online electronic portal imaging and bony setup correction remains feasible with the addition of appropriate planning target volumes. This is not suitable for the weekly high-doseper-fraction regimens but is well suited to the 19-20 fraction schedules and has been adopted in some centres in Africa.

\section{Conclusions}

Several randomised clinical trials have shown the efficacy and safety of hypofractionated EBRT for prostate cancer. Those men with compromised urinary function at baseline are at risk of late bladder toxicity; therefore, patient selection is paramount when considering hypofractionation. Hypofractionation offers economic and logistic advantages, reducing the burden of the very limited radiotherapy resources in most African countries. It also increases patient convenience. The most vital component is safe delivery, which necessitates accurate quality assurance measures and on-board imaging.

\section{Acknowledgements}

We thank Ruud Wortel, MD, for his help in collecting and reviewing the literature on hypofractionation.

\section{Competing interests}

The authors declare that they have no financial or personal relationships that may have inappropriately influenced them in writing this article.

\section{Authors' contributions}

L.I. reviewed the literature and drafted the first version of the manuscript. B.H., P.K., and H.M.S contributed to the writing of the manuscript and approved the final version.

\section{References}

1. Kingham TP, Alatise OI, Vanderpuye $V$, et al. Treatment of cancer in sub-Saharan Africa. Lancet Oncol 2013;14:e158-e167. https://doi.org/10.1016/S1470-2045 (12)70472-2

2. Parkin DM, Bray F, Ferlay J, Jemal A. Cancer in Africa 2012. Cancer Epidemiol Biomarkers Prev 2014;23:953-966. https://doi.org/10.1158/1055-9965.EPI-140281

3. Chokunonga $E$, Windridge $P$, Sasieni P, Borok M, Parkin DM. Trends in the incidence of cancer in the black population of Harare, Zimbabwe 1991-2010. Int J Cancer 2013;133:721-729. https://doi.org/10.1002/ijc.28063

4. Olapade-Olaopa EO, Obamuyide HA, Yisa GT. Management of advanced prostate cancer in Africa. Can J Urol 2008;15:3698-707.

5. Brenner DJ, Martinez AA, Edmundson GK, Mitchell C, Thames HD, Armour EP. Direct evidence that prostate tumors show high sensitivity to fractionation (low alpha/beta ratio), similar to late responding normal tissue. Int J Radiat Oncol Biol Phys 2002;52:6-13. https://doi.org/10.1016/S0360-3016(01) 02664-5

6. Incrocci L, Wortel RC, Alemayehu WG, et al. Hypofractionated versus conventionally fractionated radiotherapy for patients with localized prostate cancer (HYPRO): Final efficacy results from a randomized, multicentre, openlabel, phase 3 trial. Lancet Oncol 2016;8:1061-1069. https://doi.org/10.1016/ S1470-2045(16)30070-5

7. Dearnaley D, Syndikus I, Mossop H, et al. Conventional versus hypofractionated high-dose intensity-modulated radiotherapy for prostate cancer: 5-year outcomes of the randomised, non-inferiority, phase $3 \mathrm{CHHiP}$ trial. Lancet Oncol 2016;17:1047-1060. https://doi.org/10.1016/S1470-2045(16)30102-4

8. Lee WR, Dignam JJ, Amin MB, et al. Randomized Phase III noninferiority study comparing two radiotherapy fractionation schedules in patients with low-risk prostate cancer. J Clin Oncol 2016;34:2325-2332. https://doi.org/10.1200/ JCO.2016.67.0448

9. Catton CN, Lukka H, Gu CS, et al. Randomized trial of a hypofractionated radiation regimen for the treatment of localized prostate cancer. J Clin Oncol 2017:35:1-7. https://doi.org/10.1200/JCO.2016.71.7397

10. Loblaw A, Cheung P, D'Alimonte L, et al. Prostate stereotactic ablative body radiotherapy using a standard linear accelerator: Toxicity, biochemical, and pathological outcomes. Radiother Oncol 2013;107:153-158. https://doi.org/ 10.1016/j.radonc.2013.03.022

11. Kim DW, Cho LC, Straka C, et al. Predictors of rectal tolerance observed in a doseescalated phase 1-2 trial of stereotactic body radiation therapy for prostate cancer. Int J Radiat Oncol Biol Phys 2014;89:509-517. https://doi.org/10.1016/j. ijrobp.2014.03.012

12. Mantz C. A Phase II trial of stereotactic ablative body radiotherapy for low-risk prostate cancer using a non-robotic linear accelerator and real-time target tracking: Report of toxicity, quality of life, and disease control outcomes with tracking: Report of toxicity, quality of life, and disease control outcomes with
5-year minimum follow-up. Front Oncol 2014;4:279. https://doi.org/10.3389/ fonc. 2014.00279

13. Zimmermann M, Taussky D, Menkarios C, et al. Prospective Phase II trial of once-weekly hypofractionated radiation therapy for low-risk adenocarcinoma of the prostate: Late toxicities and outcomes. Clin Oncol (R Coll Radiol) 2016;28:386-392. https://doi.org/10.1016/j.clon.2015.12.024

14. Atun R, Jaffray $D A$, Barton $M B$, et al. Expanding global access to radiotherapy. Lancet Oncol 2015;16:1153-1186. https://doi.org/10.1016/S1470-2045(15)002 22-3

15. Voet PWJ, Dirkx MLP, Breedveld S, Al-Mamgani A, Incrocci L, Heijmen BJM. Fully automated volumetric modulated arc therapy plan generation for prostate cancer patients. Int J Radiat Oncol Biol Phys 2014;88:1175-1179. https://doi. org/10.1016/j.ijrobp.2013.12.046

16. Hussein $M$, South $C P$, Barry $M A$, et al. Clinical validation and benchmarking of knowledge-based IMRT and VMAT treatment planning in pelvic anatomy. Radiother Oncol 2016;120(3):473-479. https://doi.org/10.1016/j. radonc.2016.06.022

17. Solberg TD, Balter JM, Benedict SH, et al. Quality and safety considerations in stereotactic radiosurgery and stereotactic body radiation therapy: Executive summary. Pract Radiat Oncol 2012;2:2-9. https://doi.org/10.1016/j.prro. 2011.06.014 